\title{
Examining course syllabi: Introductory physics for life sciences
}

\author{
Remy Dou $\odot,{ }^{1,2}$ Raluca Teodorescu, ${ }^{3}$ Adrian Madsen, ${ }^{4}$ Edward F. Redish, ${ }^{5}$ and Mark Reeves ${ }^{6}$ \\ ${ }^{1}$ Department of Teaching and Learning, Florida International University, \\ 11200 S.W. $8^{\text {th }}$ Street, Miami, Florida 33199, USA \\ ${ }^{2}$ STEM Transformation Institute, Florida International University, \\ 11200 S.W. ${ }^{\text {th }}$ Street, Miami, Florida 33199, USA \\ ${ }^{3}$ Science, Engineering and Technology Unit, Montgomery College, Takoma Park, Maryland 20912, USA \\ ${ }^{4}$ American Association of Physics Teachers, College Park, Maryland 20740, USA \\ ${ }^{5}$ Department of Physics, University of Maryland, College Park, Maryland 20742, USA \\ ${ }^{6}$ Department of Physics, George Washington University, Washington, DC 20052, USA
}

(Received 1 April 2019; published 26 November 2019)

\begin{abstract}
Course syllabi are a required component of college and university courses. Syllabi present both broader course structuring practices, are a valuable "first impression" of what instructors want to offer their students, and are used as tools in course design. While best teaching practices suggest specific recommendations for syllabi development, there is little research evidence regarding their structure and use, especially in the context of introductory physics for life sciences (IPLS) courses. IPLS courses typically host students pursuing careers in the biological or health-related sciences, which are rapidly growing majors compared to other STEM degrees. Since few of these students have significant previous experience with physics, the course syllabus provides a first framing and establishment of expectations for them. In this paper, we analyzed how IPLS instructors write syllabi, how they use them in the course design process, and what experienced instructors recommend to be included in the syllabi. Furthermore, based on these analyses we compiled a set of 31 key components (organized in seven categories) for IPLS course syllabi supported by both widespread use and recommendations from experienced practitioners. We present these components and discuss implications for IPLS syllabus design. Specifically, we bring attention to the value of explicitly incorporating interdisciplinary language in syllabi narratives and learning objectives. This work provides guidance for IPLS course and syllabus design, and can also be relevant for modern interdisciplinary courses with features similar to IPLS courses.
\end{abstract}

DOI: 10.1103/PhysRevPhysEducRes.15.020143

\section{INTRODUCTION}

University instructors use course syllabi for a variety of reasons [1], from setting students' expectations regarding the rigor of a course to priming the tone of a classroom (e.g., didactic, homiletic, epistemological). Syllabi typically list office hours, describe the locations of learning resources, explain course design, describe teaching philosophy, and provide the topic schedule for an entire semester [1,2]. Contemporarily, syllabi often appear to carry legal weight, suggesting a contract between the institution, the instructor, and students in a course. Course grading guidelines, course objectives, and university policy become bylaws that hold both student and instructor accountable. At times, the perception of legality

Published by the American Physical Society under the terms of the Creative Commons Attribution 4.0 International license. Further distribution of this work must maintain attribution to the author(s) and the published article's title, journal citation, and DOI. that comes across induces instructors to include statements that preserve their right to deviate from the narrative described in their syllabi [3].

Despite the complex nature of the modern course syllabus, curriculum developers see value in its contribution to content instruction. The centers for teaching at Stanford University, University of Virginia, and Vanderbilt University, just to name a few, devote a significant portion of their energies to helping faculty develop effective syllabi [4-6]. Much of the direction these centers provide merges accepted best practices carried down from decades past with relatively recent developments in student teaching and learning $[7,8]$. The University of Virginia, for example, provides a rubric to gauge how well faculty have aligned their syllabi with specific curricular principles around learning objectives, assessment activities, schedule, and overall learning atmosphere (e.g., tone, inclusivity) [9]. Implementation of these principles and practices around syllabi development often vary both across and within institutions and departments [1].

Physics instructors adopt the same programmatic responsibility to develop course syllabi and face the same 
challenges as faculty in different fields. They, too, must consider whether or not to list learning objectives, topic schedules, expectations around course attendance, and grading policy. What finally ends up in a physics instructor's course syllabus may include a combination of materials developed by the current instructor, past instructors, department chairs, and the university governing body. Instructors who teach introductory physics for life sciences (IPLS), and similar interdisciplinary courses, carry the added burden of deciding whether and how to integrate content from more than one discipline into the course syllabus. This might include generating course objectives that address more than one content area or presenting statements informing students of the varied nature of the content they will encounter.

In this article, we answer three research questions:

1. How do IPLS instructors write syllabi?

2. How do instructors use syllabi in the course design process?

3. What do experienced IPLS instructors recommend to include in a syllabus?

The research questions have been answered using three research approaches:

- We employed a document analysis approach to examine 77 course syllabi to understand how instructors write IPLS course syllabi. These syllabi were self-selected and submitted by participants of the 2014 Conference on Introductory Physics for the Life Sciences.

- We used thematic analysis to explore interviews of 35 instructors teaching IPLS courses to understand how they use their syllabi during course preparation.

- We conducted a focus group with eight experienced instructors who pioneered and taught IPLS courses over an extended period, to establish what they consider to be essential components for an IPLS course syllabus and how they use it.

While answering our research questions following the above approaches, we have been able to identify key components of IPLS course syllabi. We present them and discuss implications for syllabi preparation.

\section{A. Introductory physics for life science courses}

Of all physics courses taught at the undergraduate level, introductory physics are where most students learn physics, with many departments offering dozens of sections every semester. These courses often exist in one of two flavors: introductory physics directed at physics and engineering majors and introductory physics directed at other majors. The latter is becoming increasingly important for physics departments, since it addresses the needs of students pursuing careers in the biological or health-related sciences, a large and growing population. At many institutions, these students have become the largest population taking introductory physics [10].
We sought to focus this study on IPLS courses not only because of the volume of students who take these courses, but also because of the situated value of the courses as gateways to STEM careers. Of all undergraduate STEM majors, the greatest number of degrees awarded goes to the biological and biomedical sciences, with greater than 100000 per year [11]. Nearly all of these students are required to take a year of physics. Some of this is driven by guidelines from the Association of American Medical Colleges and content foci of the Medical College Admission Test. Moreover, recent reports have called for a more interdisciplinary approach to the preparation of all biology majors with greater emphasis on the physical sciences $[12,13]$.

The research on the impact of a variety of curricular interventions, particularly around student learning in IPLS, has shown that carefully designed interventions can lead to increased student conceptual understanding of physics content and biological phenomena [13-15]. Despite the increased attention these courses have received from physics education researchers, and despite communities of instructors forming specifically around teaching IPLS courses $[16,17]$, their structure varies widely both across and sometimes within institutions. Everything from prerequisites to content might differ.

\section{B. Purposes of the current study}

This study contributes to IPLS course development in that it presents a survey of IPLS course syllabi from institutions across the country. Such an overview does not currently exist in the literature, and would provide a meaningful starting point for national alignment of curricular practices. We also believe that this study raises important questions about the interdisciplinary nature of IPLS and how that is reflected (or not reflected) in course syllabi. While we do not explore specific classroom practices or student outcomes, our study compares the recommendations of experts to the syllabi-related practices of instructors from a variety of institutions. Such a comparison is necessary to better understand the need for additional research (e.g., does including interdisciplinary language in syllabi reflect instructional attitudes that are manifested in classroom practices as suggested by some studies? [2]).

Moreover, the field of higher education in general lacks empirical studies around syllabi development, its uses, and effects. While "best practices" abound, as mentioned earlier, few of these cite empirical studies (see Refs. [2,18,19]). This absence is more resounding in light of studies that call to question the need for syllabi [19]. The empirical studies cited almost exclusively focus on student attitudes and perceptions toward the classroom in relation to syllabi tone (e.g., inclusive, exclusive, supportive) [19-21]. While these studies do not further link student perceptions and attitudes to student learning, they provide at least a starting point for thinking about and 
examining the impact of syllabi practices. Of the studies reviewed by the authors, no study addressed science courses in particular, nor interdisciplinary courses in general, which we believe contributes to the value of this current study as an important first step. How instructors formulate syllabi is believed to be reflective of their instructional attitudes and approaches, and gives them an opportunity to more concretely articulate unspoken attitudes [2].

The interdisciplinary nature of IPLS courses, as well as the number of course variations that currently exists, creates notable challenges for instructors. Since a syllabus provides an overview that spans an entire semester, examining it can provide complementary information from studying a single class or activity. It can provide a useful overview of the instructor's practices, teaching philosophy, and the course's content (though the kind of information that can be learned from syllabi varies). For the purpose of this study we defined a syllabus as the collection of materials used to communicate to students one or more of the following: course content, learning objectives, pedagogical approach, and/or other course-orientation information [4].

\section{Manuscript overview}

Our examination of IPLS syllabi and syllabi-related instructor practices is structured in three parts respective to three sources of data that contributed to the study: IPLS syllabi, one-on-one interviews with IPLS instructors, and a focus group interview with experienced writers of IPLS curriculum. In Sec. II we describe the context for this study, as well as the overarching methodological approach used to collect, analyze, and synthesize the data. This is followed by three sections delving into one of the three parts of this study listed above. Section III describes the methodological approach, analysis, and outcomes related to IPLS syllabi data. Section IV describes similar components related to the one-on-one interview data, and in Sec. V we address the focus group data. Finally, in Sec. VI we synthesize the results and themes gleaned from the analyses.

\section{OVERARCHING METHODOLOGICAL FRAMEWORK}

This study is situated in the context of a much larger movement around the reformation of IPLS courses. This movement has been carried out by practitioners in the field of physics education, including some of the authors of this manuscript. This purposeful focus on IPLS started prior to the 2014 Conference on Introductory Physics for the Life Sciences. At the time of publication, the authors of this manuscript were involved in an expansive NSF-funded project that aimed to provide meaningful resources for instructors teaching IPLS courses (see Ref. [22]). As part of the formative evaluations that guided this project, the authors undertook the current study to better understand the practices and needs of IPLS instructors with regard to syllabi formation and course development. We drew data from the syllabi submitted during the 2014 conference, from one-on-one interviews of IPLS instructors at institutions across the country, and from a focus group interview with "expert" IPLS instructors as defined by their membership in the IPLS community and their experience developing IPLS curricula.

Our collection of three types of data follows a combination of Creswell and Plano Clark's [23] parallel convergent and explanatory sequential designs for mixed methods research, which they refer to as a "multiphase" design. A parallel convergent design calls for data collection and analyses from multiple quantitative or qualitative sources that provide differing but complementary perspectives around one or more research questions. As such, our document analyses of syllabi occurred in tandem with our collection and analyses of instructor interviews. Subsequently, we adopted an explanatory sequential design to explore and expand findings from our prior data collections and analyses. We did so by hosting a focus group interview with expert IPLS instructors. The protocol for the focus group was informed by the prior syllabi and interview analyses. We should also note that although document analysis is not considered strictly a quantitative research methodology, our particular approach emphasized a quantitative perspective [24].

\section{HOW DO INSTRUCTORS WRITE SYLLABI?}

In March of 2014 the National Science Foundation (NSF) funded an IPLS conference that took place in Arlington, VA with the purpose of bringing together faculty teaching introductory physics courses to student populations of pre-med, pre-health, and life science majors [17]. The conference focused on both the content and pedagogy of IPLS courses, laboratory work, as well as highlighted relevant education research in IPLS. Participants were invited through word of mouth and electronically through existing collegial networks known to the conference organizers.

At the end of the conference, participants were encouraged to submit their syllabi electronically: 77 syllabi were submitted by 39 unique authors from 38 different institutions. The dates for the syllabi ranged from the fall of 2008 to the spring of 2014. Table I shows the types of institutions from which syllabi came, Table II shows the classroom size

TABLE I. The institutional affiliation of the instructors who submitted the $N=77$ syllabi that have been analyzed.

\begin{tabular}{lc}
\hline \hline Institution & Percent of syllabi \\
\hline Research university (Ph.D. granting) & 45 \\
4-year teaching university & 29 \\
4-year college & 23 \\
2-year college & 3 \\
\hline \hline
\end{tabular}


TABLE II. The class size of the courses featured in the $N=77$ syllabi that have been analyzed.

\begin{tabular}{lc}
\hline \hline Class size & Percent of syllabi \\
\hline Small (0-25 students) & 13 \\
Medium (26-50 students) & 37 \\
Large (more than 51 students) & 49 \\
Not specified & 1 \\
\hline \hline
\end{tabular}

TABLE III. The percentage of the $N=77$ syllabi explicitly addressing students pursuing particular majors. This did not necessarily reflect whom the course was actually intended for.

\begin{tabular}{lc}
\hline \hline Majors explicitly addressed & Percent of syllabi \\
\hline Biology majors only & 3 \\
Pre-health majors only & 6 \\
Biology and pre-health majors & 40 \\
Biology, pre-health, and chemistry majors & 5 \\
Biology, pre-health, and IT majors & 1 \\
Generic, all majors, or not explicit & 40 \\
Non-physics majors & 5 \\
\hline \hline
\end{tabular}

addressed by the syllabi, and Table III shows the types of majors these syllabi were directed toward.

\section{A. Methodology}

We analyzed each of the 77 syllabi to identify its components. We employed document analysis techniques widely accepted in qualitative research, drawing primarily from Bowen and O'Leary [25,26]. Document analysis is a common methodology employed in mixed methods research that allows researchers to triangulate findings from other data sources [25]. Our application of document analysis includes a quantitative content analysis (QCA), which is defined as "segmenting communication content into units, assigning each unit into categories, and providing tallies for each category" [24], (p. 5). While Bowen [25] warns against the exclusive use of QCA in document analysis, he does support its use as a "first-pass document review, in which meaningful and relevant passages of text or other data are identified" [24] (p. 32). We then drew from those findings themes pertinent to our study.

Our first step in analyzing the syllabi was to develop a list of syllabi components (i.e., categories) for content analysis relevant to our research questions. This included taking into account the contexts in which the syllabi were created and collected, as well as their contents. The components of our analysis were further informed by the education literature, by best practices of syllabi and course design [4-8], and by the unique characteristics of the IPLS syllabi. These components were shared with and agreed upon by all the authors to establish face and content validity. To further establish validity of categories, the first and second author categorized a subset of syllabi $(n=5)$ until 100\% agreement was achieved. The first author then examined all the syllabi, one at a time, noting the presence or absence of various characteristics relevant to each of the components identified. This information was tallied and converted into percentages out of the total number of syllabi. The choice of having the first author code all of the syllabi was made in order to decrease researcher bias as many of the syllabi were contributed by instructors who had been close colleagues of the remaining authors. Moreover, being a relatively recent member of the IPLS research community, the first author provided less subjectivity.

Table IV shows the syllabi categories considered and an explanatory statement for each component. Additionally, percentage counts of components across syllabi are included to provide a sense of frequency. Ubiquitous components like institution name, course name, instructor name, and semester have been left out of this table. Some components required more than simple binary notation. For example, the number of learning objectives present required a count and the math course prerequisites required a nominal term. The tallies were later examined by the authors who identified emergent patterns from the quantitative data extracted. These patterns, which we present below, were defined by the authors through both synchronous and asynchronous group discussion. This complementary application of QCA and thematic analysis is common to document analysis; see Ref. [27].

\section{B. Components germane to most syllabi}

All or nearly all syllabi contained basic information about the instructor, institution and course name, year and semester, and course type. Only about a quarter of the syllabi included a link to a course website-it was unclear whether the lack of inclusion signified that a website did not exist. The syllabi narratives primarily targeted biology and pre-health majors, though when not focused on these student populations, the narratives were directed at students of any major. We expected this, given that IPLS courses are typically offered to students who are required to take introductory physics, but are not necessarily biology majors. The majority of these students tend to be life science majors, but that is not exclusively the case. The American Chemical Society (ACS), for example, requires chemistry majors to take two semesters of physics and their accompanying laboratory courses [29]. The ACS, as well as the plurality of medical schools in the country, also recommend, but do not require, that students take physics with calculus. We also saw this reflected in the syllabi where only $32 \%$ required calculus experience, while the rest required prior knowledge in algebra and/or trigonometry.

\section{Learning objectives}

The majority of instructors included both learning objectives and topic sequences. The former were explored 


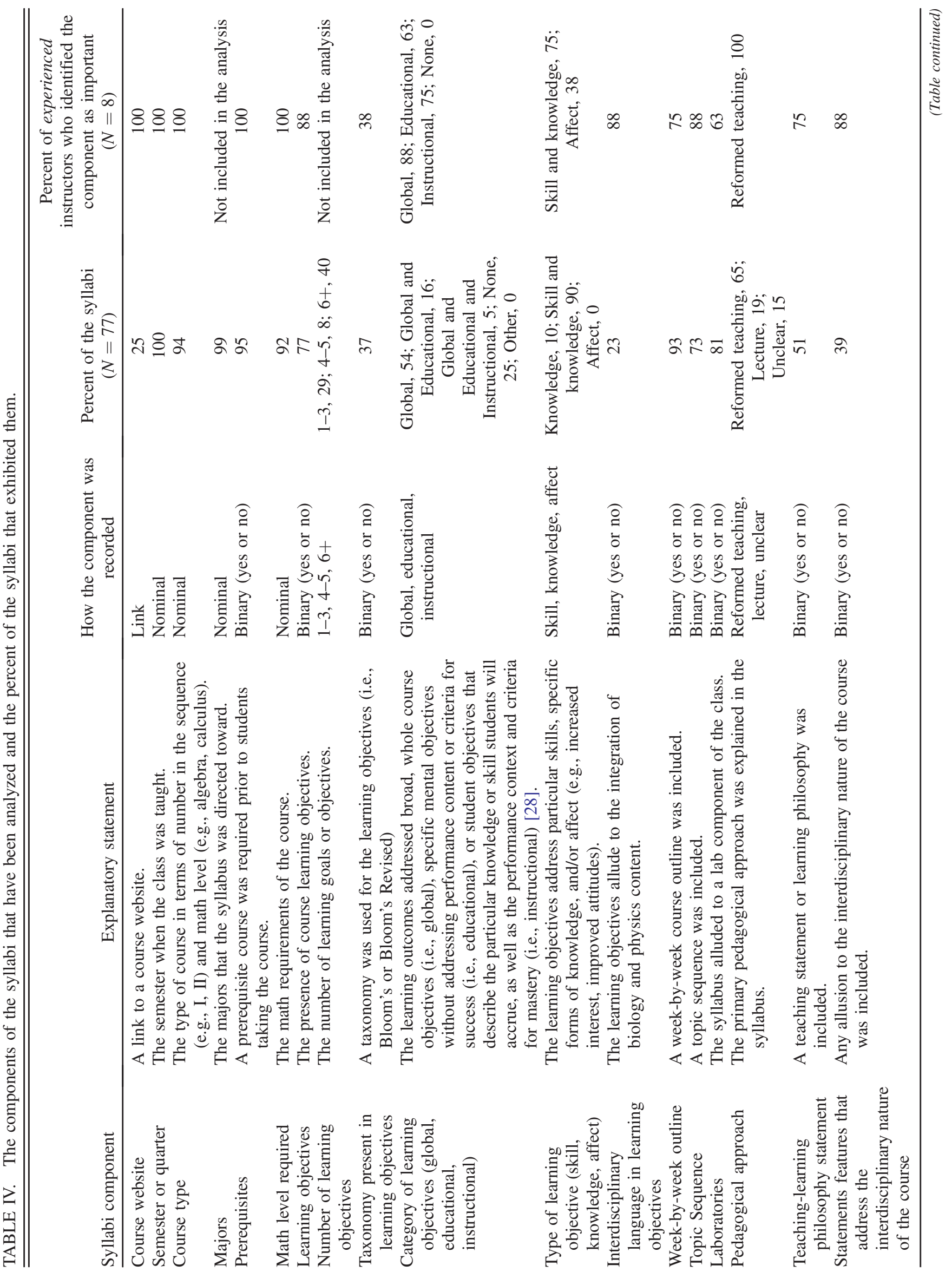




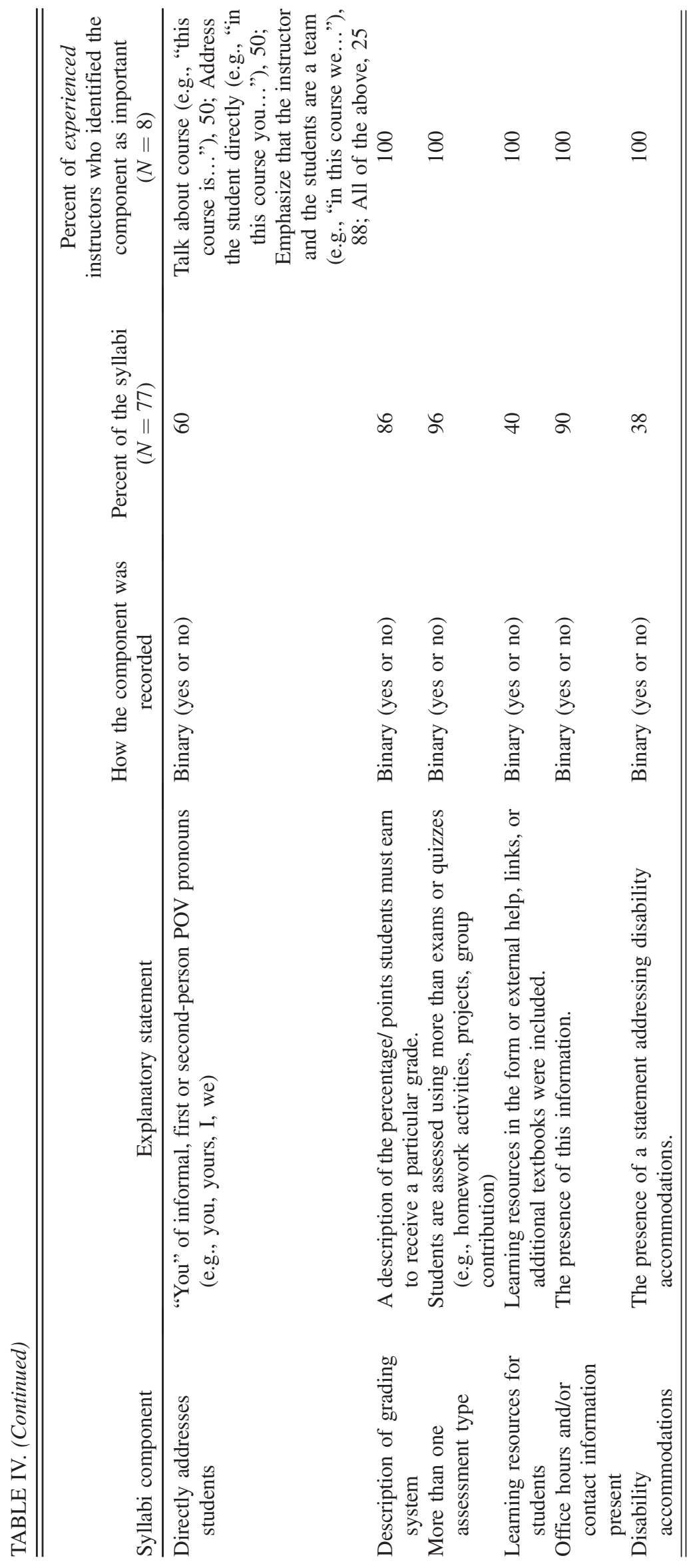


in terms of categories and types. We identified learning objectives across three categories: global (address broad course topics), educational (address specific content knowledge), and instructional (address students' content knowledge and criteria for success) [30].

We found that learning objectives almost exclusively focused on global and educational objectives, but did not include instructional objectives that provide more explicit standards for determining performance success. These objectives were also grouped into three other categories: objectives that focus on knowledge, objectives that focus on skills, and objectives that focus on affect (e.g., interest in physics). Learning objectives exclusively addressed knowledge and/or skills, e.g.,

"[students] will understand the fundamentals of classical physics and will have developed the problem-solving skills needed for answering both physics and nonphysics related questions".

No learning objective addressed student affect (e.g., students will gain confidence in their ability to solve physics-related problems).

In addition to learning objectives, $73 \%$ of instructors included topic sequences and the great majority of these were presented using a week-by-week schedule.

We could not identify any relationship between the quality or the number of learning objectives and the type of institution.

\section{Assessment and reformed teaching strategies}

Assessment of student learning involved multiple instruments, including but not limited to the use of exams in combination with group or laboratory activity, clicker questions, and homework, indicating a move away from traditional exam-only evaluation of learning objectives. This is further supported by explicit allusion to the use of reformed teaching strategies in $65 \%$ of syllabi (e.g., use of personal response systems, integrated lab, collaborative activities).

Most syllabi described inclusion of reformed teaching strategies, though our metrics for what counted as reformed teaching were very inclusive. Students were typically presented with a topic outline of the course and sometimes also a teaching philosophy statement from the instructor. Most of the syllabi included broad (i.e., global) learning goals regarding the expected student knowledge and skills built as a result of taking the course.

\section{E. The interdisciplinary character of the course}

The syllabi differed on what we considered to be an important characteristic: the interdisciplinary nature of IPLS. Few of the syllabi contained any interdisciplinary language. In fact, most syllabi (i.e., 61\%) did not contain interdisciplinary language despite catering predominantly to nonphysics majors. However, 39\% did include such statements, e.g.,

"this is the first in a two-semester sequence of...[an] algebra-based introduction to general physical principles in the areas of mechanics, energy, thermodynamics with conceptual and quantitative applications to phenomena in the life and health sciences,"

The absence of interdisciplinary statements was more apparent when examining learning objectives specifically. Seventy-seven percent of syllabi did not include interdisciplinary language in the course learning objectives. This seems significant to us given the recent calls to situate physics content in biological contexts, particularly within IPLS courses, for the purpose of increasing student learning and engagement $[12,13,15,16]$.

The NEXUS/Physics course at the University of Maryland was an example of an IPLS curriculum that attempted to do so, and its reformed characteristics (i.e., topic sequence and pedagogical approach) were reflected in the syllabus [28]. The curriculum builds off students' prior knowledge and skills in biology and chemistry "in a way that creates a multidisciplinary scientific approach" [28], (p. 372). In doing so, the developers restructured the traditional physics topic sequence. For example, they limit the attention given to forces while expanding the discussion around energy, fluids, entropy, enthalpy, and microscopic random motion. Pedagogically, the course also differs from the traditional by focusing on student construction of conceptual understanding rather than memorization of formulas or problem-solving algorithms. These characteristics were not apparent in most syllabi.

Although we understand that the absence of interdisciplinary statements does not mean that interdisciplinary content does not appear in the classroom, as revealed in the interviews, it could suggest that instructors may not see this component as a defining characteristic of IPLS and/or the community of IPLS instructors has not come to an agreement on how to present the intersection of biology and physics.

Math also vies for the attention of instructors who want to adopt the practices recommended by national reports like BIO2010 [13], and those encouraged by funding agencies. One of our instructors highlighted these reports and the pressure on incorporating math into his IPLS course this way,

"[the course] is sort of geared towards reducing the algebra population, anticipating the Howard Hughes initiative to boost the quantitative skills of the students in pre-health".

Regarding the components featured by syllabi we can see that 18 out of the 28 components listed in Table IV were present in more than $50 \%$ of the syllabi and we organized 
them in Table XII. The remaining components were present in less than 50\% of the syllabi. Only "affect" failed to show up in any of the syllabi. Affect was a component of analysis included as a result of our review of the literature. Absence of affective objectives may not necessarily result from faculty neglect, but from lack of established practices for assessing affect.

\section{HOW DO INSTRUCTORS USE SYLLABI DURING THE COURSE DESIGN PROCESS?}

To understand how the components of the syllabi are used by instructors in their course preparation process, we carried out and analyzed interviews with 35 instructors teaching IPLS courses at institutions across the country. These interviews took place in tandem with syllabi analysis. Some of these interviews were conducted in person and some remotely. Table V shows the interviewees' affiliation, while Table VI details their teaching experience.

Syllabi-related practices were not the sole reason for conducting the interviews. As part of the broader project on IPLS course development and reformation, we were interested in a number of issues, including learning about what resources instructors use regularly (e.g., textbook, websites, vendor materials), what additional resources they might be willing use, and challenges they encounter during the process of course development. As such the interview protocol addressed broader issues around the development of IPLS course curricula, though this certainly included syllabi-related practices. Refinement of the interview protocol occurred through an iterative discursive process undertaken by the authors, as well as team members of the broader project, taking care to align protocol questions to both the guiding research questions of the broader project, as well as the specific research questions listed in Sec. I of this study.

TABLE V. The affiliation of the interviewees $(N=35)$.

\begin{tabular}{lc}
\hline \hline Institution type & Percent of instructors \\
\hline 4-year research university & 65 \\
4-year teaching university & 23 \\
4-year college & 2 \\
2-year college & 10 \\
\hline \hline
\end{tabular}

TABLE VI. The teaching experience of the interviewees.

\begin{tabular}{lc}
\hline \hline Teaching experience & Percent of instructors \\
\hline First time teaching an IPLS course & 27 \\
$\quad$ or taught one a few times. & \\
Taught IPLS courses for a long time. & 44 \\
Taught IPLS courses for a long time & 29 \\
$\quad$ and developed IPLS materials. & \\
\hline \hline
\end{tabular}

Some of our interviewees mentioned their use of the syllabus spontaneously in response to broad questions (e.g., what is your process for developing your IPLS course prior to the start of the semester). In these cases, we asked follow-up questions to better understand their syllabi related practices. In cases when they did not directly address their syllabi-related practices, we specifically included the following queries:

- Tell me about your process for creating your syllabus.

- How do you use your syllabus once you have created it?

- Have you used someone else's syllabus? How did you use it for your course?

The first author examined responses to these questions and also searched all interview transcripts for any mention of the words "syllabus,", "syllabi," "learning objective," "learning outcome," "learning goal," and "topic sequence" to inform the current study. Responses and excerpts were coded using a post hoc open coding technique, allowing for the development of codes more closely aligned with interviewees' responses and less prone to bias arising from presuppositions. The coded excerpts were then categorized into themes based on similarities of ideas presented. The themes addressed in this study include those relevant to syllabi components mentioned, the instructors' beliefs about the purpose of their syllabi, as well as collaborative practices around syllabi use. Table VII summarizes our findings.

Some of those interviewed had submitted syllabi examined in the first part of this study and some had not. What they shared in common was that all the interviewed faculty had taught or were at the time teaching an IPLS course. A large majority represented research institutions, while the remaining were affiliated with a teaching college or university. Regarding their teaching experience, a greater number of interviewees had been teaching for many years, while a fewer number were either teaching novices or experts who had developed IPLS materials.

Our interviews with physics faculty regarding their course-design process provided us with additional insight about syllabi use. We identified 13 ways in which instructors used or mentioned the syllabi, ranging from just getting ideas to carefully designing an entire course based on the syllabus. Most commonly mentioned was "updating the syllabus from year to year" using past syllabi, as well as colleagues', to generate new ideas or topics for upcoming courses. Some of the faculty mentioned sharing syllabi as a way of aligning courses taught by different instructors. Few spoke about their syllabus as a representation of course design, but the document seems to serve as a tool to track changes in the overall structure of a course (e.g., topic sequence, schedule, or pacing).

Our prior analysis of IPLS syllabi revealed that nearly all syllabi included week-by-week course outlines that help with schedule and pacing, as well as topic sequences. As mentioned previously, we also found that the majority of 
TABLE VII. How the interviewees used the syllabi or talked about it in their course preparation process $(N=35)$. Some interviewees performed more than one of the actions listed. Note this list reflects what faculty shared with us during interviews, but may not be inclusive of all their practices.

\begin{tabular}{lc}
\hline \hline Action related to the syllabus & $\begin{array}{c}\text { Percent of } \\
\text { instructors }\end{array}$ \\
\hline $\begin{array}{l}\text { Used the syllabus to "get ideas" } \\
\text { Consulted others' syllabi for ideas }\end{array}$ & 15 \\
$\begin{array}{l}\text { Consulted the list or the order of topics from the } \\
\text { syllabus }\end{array}$ & 15 \\
$\begin{array}{l}\text { Consulted the syllabus to rearrange the course } \\
\text { pacing or schedule }\end{array}$ & 17 \\
$\begin{array}{l}\text { Prepared the weekly activities based on a weekly } \\
\text { outline from the syllabus }\end{array}$ & 6 \\
$\begin{array}{l}\text { Mentioned the learning objectives from the } \\
\text { syllabus }\end{array}$ & 6 \\
$\begin{array}{l}\text { Designed the entire course (e.g., lectures, } \\
\text { homework sets, assessments) around the } \\
\text { learning objectives from the syllabus. }\end{array}$ & 3 \\
$\begin{array}{l}\text { Mentioned having to include particular topics or } \\
\text { objectives in the syllabus for accreditation }\end{array}$ & 9 \\
purposes & \\
$\begin{array}{l}\text { Shared syllabus with other instructors for course } \\
\text { alignment purposes }\end{array}$ & 6 \\
$\begin{array}{l}\text { University provided syllabus template } \\
\text { Mentioned the syllabus, but didn't use it } \\
\text { explicitly }\end{array}$ & 3 \\
$\begin{array}{l}\text { Syllabus' content outline mirrors textbook's } \\
\text { content outline }\end{array}$ & 6 \\
$\begin{array}{l}\text { Mentioned updating syllabus from semester to } \\
\text { semester or year to year }\end{array}$ & 20 \\
$\begin{array}{l}\text { Mentioned other resources that serve similar } \\
\text { purposes as a syllabus (e.g., using Blackboard } \\
\text { or Canvas to share course grading policy or } \\
\text { course schedule, using textbook to share } \\
\text { course topic outline) }\end{array}$ & 47 \\
\hline \hline
\end{tabular}

syllabi carry learning objectives. Some of the faculty who participated in these interviews alluded to referenced learning objectives listed on syllabi as an aspect of course-design and/or accreditation.

Although almost half of instructors made no allusions to their syllabi, some of these referenced the use of other tools that seem to parallel the purpose ascribed to syllabi. For example, some faculty described their use of their textbook's table of contents as the topic sequence of their course. Others mentioned the use of a learning management system (LMS) like Canvas and Blackboard to convey information traditionally included in syllabi, including grading policies and course schedules. (In some sense, setting up an LMS can be seen as an interactive, on-line, adaptable syllabus. It would be an interesting research question to explore how LMS users are replacing and expanding the traditional concept of syllabus and how it can best be set up to fulfill a similar role.)
Regarding the components featured in Table IV, four categories seem to be used by the instructors during their course preparation: learning objectives, week-by-week outline, topic sequence, and assessments.

\section{WHAT DO EXPERIENCED IPLS INSTRUCTORS RECOMMEND TO INCLUDE IN A SYLLABUS?}

The last part of our research sought to establish to what extent the findings from previous sections were validated by instructors with experience in designing and teaching IPLS courses.

\section{A. The demographics of our experienced instructors}

We conducted a focus group with eight experienced instructors who received National Science Foundation awards to develop IPLS courses, developed and implemented them, and taught these courses for several years. Table VIII shows the teaching experience of our instructors. Our experienced instructors taught classes of different sizes in various types of institutions. Tables IX and X show the corresponding details.

\section{B. The components of a standard syllabus our experts considered valuable}

Informed by the synthesized findings from our document analysis, our instructor interviews, as well as field notes that captured information we thought was pertinent during the instructor interviews, we developed an activity to gather the perspectives of experienced IPLS instructors, which we later compared to that of findings from prior data collections. We asked participants to complete the activity shown below in which we presented them with the syllabi

TABLE VIII. The teaching experience of the focus group participants $(N=8)$.

\begin{tabular}{lc}
\hline \hline Instructor & No. of years teaching an IPLS course \\
\hline Instructor 1 & 30 \\
Instructor 2 & 20 \\
Instructor 3 & 15 \\
Instructor 4 & 12 \\
Instructor 5 & 10 \\
Instructor 6 & 10 \\
Instructor 7 & 5 \\
Instructor 8 & 4 \\
\hline \hline
\end{tabular}

TABLE IX. The institutional affiliation of the focus group participants $(N=8)$.

\begin{tabular}{lc}
\hline No. of instructors & The type of institution in which they taught \\
\hline 3 & 4-year research university \\
2 & 4-year teaching university \\
3 & 4-year college \\
\hline \hline
\end{tabular}


TABLE X. The size of the classes taught by the focus group participants $(N=8)$.

\begin{tabular}{lc}
\hline \hline No. of instructors & The class size in which they taught \\
\hline 3 & Medium (26-50 students) \\
5 & Large (more than 51 students) \\
\hline \hline
\end{tabular}

components that had been identified in the previous sections and asked them to establish which of these components proved to be useful in their teaching IPLS courses. The activity was followed by an open discussion where participants were invited to share their responses to the activity, as well as provide reasons for their choices.

Activity: Think of your own experience teaching IPLS courses. Specifically, think of what components you needed in your IPLS syllabus to best assist you in your teaching and in providing students with what they needed. Below is a list of syllabus components. Based on your experience, please circle all the components that you think are relevant and important for an IPLS course syllabus.

Note:

- A syllabus is both a document about the course content, goals, and elements and a guide for students to the kind of teaching and learning they can expect in your class [4].

- For the purpose of this activity, by syllabus we mean the collection of materials that you use to organize the course content, learning objectives, and pedagogical approach, and to orient the students during the instructional period.

- If your institution has mandatory syllabi templates or formats, please disregard them for this activity. Please complete the activity relying entirely on your experience.

1. Administrative components (circle all that apply): Institution, course name, course website, instructor name, year, semester, course type, prerequisites (e.g., math, chemistry, biology)

2. Course-organization components (circle all that apply): Topic sequence, week-by-week outline, lab details (if applicable)

3. Learning-related components (circle all that apply): a. Learning objectives:

i. global (whole course objectives);

ii. educational (specific mental objectives without addressing performance content or criteria for success);

iii. instructional (describe the particular knowledge or skill students will accrue, as well as the performance context and criteria for mastery)

iv. affect-related objectives: (e.g., confidence to solve problems)

b. Information about the course level of thinking (e.g., taxonomy-based) c. Information about the interdisciplinary nature of the course (e.g., biology, chemistryrelated details)

d. Pedagogical approach

e. Teaching statement or learning philosophy

f. Language that directly addresses strategies for students' success

4. Assessment-related components:

a. Description of grading approaches

b. Description of all types of assessment used (e.g., homework, quizzes, etc.)

5. Components related to student support:

a. Office hours

b. Additional learning resources

c. Disabilities information

6. Institution-specific required information (if not listed above)

Based on your experience, are there any additional components that you think need to be included on an IPLS syllabus?

In the activity, we emphasized in boldface the syllabi components that we added to the expert instructors' activity in addition to the ones presented in the list from Table IV. Despite not being among the most popular in the 77 syllabi that we analyzed in Sec. III, these components were added because we believed the experienced instructors' opinions about them could provide valuable research findings.

Column four of Table IV summarizes the components found in the 77 syllabi submitted as a result of the 2014 IPLS conference described in Sec. III. Column five shows what experienced IPLS instructors found important and useful to include in a syllabus.

One of the authors of this article conducted the focus group. The relative brevity of the focus group interview permitted the authors to familiarize themselves well with the transcript. This process included one basic readthrough of the transcript and a second more detailed exploration that involved a purposeful comparison of similar themes identified in prior analyses. This was followed by a discussion of findings.

While there seems to be substantial agreement for about 14 components, there are also some notable differences:

All experienced instructors indicated that syllabi should include links to course websites, while only a quarter of submitted syllabi included this component.

Even though this discrepancy might be attributed to oversight on the part of the instructors, it is equally possible that in many cases the courses represented by syllabi without weblinks simply did not make use of an online site or make use of a learning management system. Alternatively, learning management systems may be so embedded in the structure of courses at an institution that instructor do not see a need to call those out. This would 
change the way we interpret the percentage of syllabi without links.

Perhaps our most significant finding is that

our experienced instructors suggest listing clear learning objectives across their various types (i.e., global, educational, and instructional) at a much higher level than is seen in the full collection of syllabi.

While more emphasis was placed on global learning objectives, instructional objectives that describe the kind of knowledge and skills students should accrue came at a close second (i.e., $88 \%$ recommended vs $75 \%$, respectively). A significant fraction of our experts believed that affect should be a part of the learning objectives for an IPLS course (e.g., you will develop interest in physics), while none of the submitted syllabi mentioned affect in their listed learning objectives.

Another finding worth noting is that

7 out of the 8 experts recommended the use of interdisciplinary language addressing both biology and physics content throughout a syllabus.

Moreover, they suggested this kind of interdisciplinary language should be made explicit in the course learning objectives. Despite this nearly unanimous recommendation from our group of experienced instructors, less than half of all submitted syllabi employed such language, and less than a quarter included interdisciplinary language in their learning objectives. The significance of this lies in the intent of these courses to meet the needs of non-physics STEM majors, particularly life science, pre-med, and health majors. IPLS courses tend to differ from those offered to physics and/or engineering majors with the most common adjustment being the mathematics requirements.

The tension between tailoring physics courses to nonphysics majors and the absence of any interdisciplinary language might suggest a lack of uniformity in the level of interdisciplinary content included in the course. In fact, clear uniformity exists in the way mathematics is incorporated, with few IPLS courses requiring more than a precalculus or trigonometry background. Tying in other content areas poses significant challenges for instructors.

When asked about other components (besides the ones featured in Table IV) that they found useful for the syllabi, the experienced instructors listed the following: purchasing information (i.e., books, manuals), information on how students can get help if struggling, regrades and make-ups information, absentee policy, statements about equity and inclusivity, honor code, code of conduct, religious exemptions, snow cancellations, and emergency evacuation.

\section{How our experienced instructors used their syllabi}

Following the group activity, we conducted a focus group with the expert instructors, in which one of the
TABLE XI. Additional syllabus-related actions pointed out by the expert instructors $(N=8)$.

Action related to the syllabus

Direct students back to the syllabus during the semester

Remind students when transitions will happen

Justify grades to confused students

Establish contract with students regarding commitments

questions we asked was "How do you use the syllabus in your teaching or teaching preparation?" Their answers mirrored those indicated by the interviewed instructors $(N=35)$, which were summarized in Table VII. Additional uses not included in Table VII are included below in Table XI.

Tables VII and XI suggest that the syllabus is not only a tool that offers an overview of the course, but also an active document that is used by IPLS faculty during a term. Perhaps equally important are the actions' wide range of applicability.

IPLS instructors use the syllabi

- to organize and guide their teaching and teaching pacing,

- to communicate with students,

- to build on previous instructors' expertise,

- to communicate with other instructors,

- to abide to university regulations, and

- to comply with accreditation standards.

This wide range of actions calls for adequately crafted syllabi components.

Building on the research presented in Secs. III and IV, the research related to IPLS expert instructors (summarized in Tables IV, VII, and VI) enhances the list of syllabi components identified in the syllabi analysis, and suggests that an optimal design for an IPLS syllabus may contain the components presented in Table XII. We grouped these components into seven categories that represent their most common application.

\section{SUMMARY AND CONCLUSIONS}

Designing a useful syllabus is a challenging task, especially in the context of interdisciplinary courses like IPLS. IPLS courses tend to host students who pursue careers in biological or health-related sciences. These majors gain continual popularity and IPLS courses often serve as gateway courses for STEM careers. The interdisciplinary nature of IPLS courses, as well as the number of course variations that currently exist, creates significant challenges for instructors. To make matters more complicated, we know from our examination of syllabi that despite serving a plurality of life science majors, IPLS courses also often have to address the needs of students in other majors.

We researched how instructors write syllabi, how they use them, and how existing best practices align with these 
TABLE XII. Summary of the syllabi components. Italicized descriptors indicate key syllabi components identified in most of the IPLS syllabi analyzed $(N=77)$. The remaining components were identified using the interviews and the focus group described in Secs. III and IV.

Administrative components

\section{Institution}

Course name

Course website

Instructor name

Year, semester

Course type

Prerequisites (e.g., math, chemistry)

Purchase Information (e.g., books, manuals)

Course organization components

Topic sequence

Week-by-week outline

Lab details

Learning-related components

Learning objectives (global, educational, instructional, and affect-related)

Pedagogical approach

Teaching philosophy

Information about the interdisciplinary nature of the course

Strategies for student success

MCAT-related information

Assessment-related components

Grading policy

Descriptions of assessments (e.g., quizzes, tests, reports)

Student support components

Office hours

Additional learning resources

Disabilities information

Make up work

Absence policy

Institution specific (required) information

Statements about equity and inclusivity

Code of conduct

Religious exemptions

Weather cancellation policy

Emergency evacuation information

Accreditation specific (required) information

actions [4-9] using three procedures: analyzing syllabi submitted to the IPLS conference, interviewing IPLS instructors, and conducting a focus group with a set of highly experienced IPLS instructors.

Based on this research we compiled a list of 31 components (featured in Table XII) that we organized into seven categories: administrative, organizational, learningrelated (metacognitive), assessment-related, components related to student success, institution-specific required information, and accreditation-specific required information. These components are meant to serve the wide range of syllabi purposes that our research determined, which include organizing and guiding the teaching and teaching pacing, helping instructors communicate with students, helping them build on previous instructors' expertise and communicating with other instructors, abiding by university regulations, and complying with accreditation standards.

Among other findings, our research revealed a significant gap between the value that experts interviewed in our study ascribed to a variety of metacognitive development, most particularly in interdisciplinary language in syllabi and the syllabus writing practices of instructors represented in our study. Nearly all experts agreed that interdisciplinary language, i.e., directly addressing the multicontent nature of the course, belong in both the syllabi narrative and the course learning objectives. Of these two features, including interdisciplinary language in the course objectives has wider-reaching implications. Nevertheless, interdisciplinary language was rarely mentioned in the syllabi we examined, if at all. We hope the findings of this study will spur research on the instructional effects of including such language and on how the use of interdisciplinary language in the syllabi may or may not serve as a proxy for instructional practices.

Given the importance placed on course objectives as guidelines for the development of instruction, assessments, and adherence to accreditation requirements, a shift toward more interdisciplinary language may motivate or follow the transformation of IPLS courses. There is evidence that students would benefit from learning physics content in authentic contexts relevant to life science majors. This may have the effect of supporting physics learning, reinforcing life science concepts, encouraging students to find personal meaning and interest in the subject matter, and facilitating students' ability to transfer physics principles across subject-matter boundaries [31,32]. Such outcomes would align with the recommendations of stakeholders in both physics and life science fields [12,13,15-17,26].

We believe that this work will help IPLS instructors design their syllabi, not only by accounting for the components we identified, but also through the comparisons we presented between instructors with different levels of teaching experience. A syllabus can have a significant impact on the teaching environment and students affects. As one of the experienced instructors in our focus group put it: "If I had known how to explain the interdisciplinarity aspect of my IPLS course in the syllabus, I would have avoided many of my students' frustrations."

We should also note almost all of the collected syllabi failed to provide students with clear instructional objectives. This lack of communication may foster ignorance or create confusion as to what students are expected to learn throughout the course. Despite the need for more research around the effects or value of articulating clear instructional objectives, existing studies suggest these are cornerstones of teaching practices [33]. The outcomes of our study 
prompt us to encourage instructors and physics departments to think carefully about articulating learning objectives and examining the value of having clearly articulated learning objectives on course development.

Besides supporting IPLS instructors, we believe our work can also have applications beyond the area of IPLS courses, and could inform the design of syllabi for other interdisciplinary courses as well as university- or college-wide syllabi templates. In a rapidly changing educational environment in which interdisciplinarity plays an increasingly major role, proactive educators and researchers may want to employ research procedures like the ones presented in this article to support their syllabi design for interdisciplinary courses. The same is true for colleges and universities that adopt an institution-wide syllabi template model.

The implications of our study should be interpreted in light of the limitations of our findings. A significant limitation of our study lies in the context from which IPLS syllabi were collected, i.e., the IPLS conference. Given that participants to the conference were self-selected, it is likely that they incorporated more of the widely accepted best practices for introductory interdisciplinary physics than the typical faculty or instructor. Moreover, our study does not include adequate representation of faculty from small, two-year colleges. It is plausible that syllabi writing and course design practices differ at these institutions than the ones better represented here, and this is a fruitful area of future research. Finally, we want to point out that although we featured a frequency analysis of expert responses in Table IV, these numbers should not be broadly generalized as they only represent the experiences of eight individuals.

While there is great value of long-term best practices and recommendations for syllabi design, the student population, teaching tools, pedagogies, and career requirements for graduates are continually changing. IPLS courses should be constructed in light of recent calls for interdisciplinary language and learning objectives.

An interesting extension of our work would be to explore the perspectives of students both for determining alignment between what components instructors find valuable in a syllabus vs what students find valuable, as well as measuring the impact these components actually have. Syllabi reflect and inform course frameworks and instructional practices, and their development should be carried out with purposefulness using proven and research-based practices whenever possible.

\section{ACKNOWLEDGMENTS}

This work is supported by NSF Grant No. 1624158 . We thank Robert Hilborn, Dawn Meredith, Nancy Beverly, Nancy Donaldson, Catherine Crouch, Bruce Mason, Vashti Sawtelle, and Ben Geller for valuable feedback.
[1] D. V. Habanek, An examination of the integrity of the syllabus, Coll. Teach. 53, 62 (2005).

[2] J. M. Slattery and J.F. Carlson, Preparing an effective syllabus: Current best practices, Coll. Teach. 53, 159 (2005).

[3] P. Wasley, The syllabus becomes a repository of legalese, Chron. High. Educ. 54, 1 (2008).

[4] https://teachingcommons.stanford.edu/resources/coursepreparation-resources/creating-syllabus.

[5] http://cte.virginia.edu/resources/syllabus-rubric/.

[6] https://cft.vanderbilt.edu/guides-sub-pages/syllabus-design/.

[7] R. F. Mager, Preparing Instructional Objectives (Fearon, Palo Alto, CA, 1962).

[8] K. Bain, What the Best College Teachers Do (Harvard UP, Cambridge, MA, 2004).

[9] https://cte.virginia.edu/sites/cte.virginia.edu/files/SyllabusRubric-Guide-2-13-17.pdf.

[10] National Center for Education Statistics, Digest of Education Statistics, 2015 (U.S. Department of Education, Washington, DC, 2016).

[11] National Center for Education Statistics, Digest of Education Statistics, 2016 (U.S. Department of Education, Washington, DC, 2018).

[12] AAMC-HHMI Committee, Scientific Foundations for Future Physicians (AAMC, Washington, DC, 2009).
[13] National Research Council, Bio 2010: Transforming Undergraduate Education for Future Research Biologists (National Academy Press, Washington, DC, 2003).

[14] https://www.acs.org/content/dam/acsorg/about/governance/ committees/training/2015-acs-guidelines-for-bachelorsdegree-programs.pdf.

[15] C. Brewer and D. Smith, Vision and Change in Undergraduate Biology Education: A Call to Action (AAAS, Washington, DC, 2011).

[16] D. C. Meredith and E. F. Redish, Reinventing physics for life science majors, Phys. Today 66, 38 (2013).

[17] American Association of Physics Teachers, Conference on Introductory Physics for the Life Sciences Report (AAPT, Washington, DC, 2014).

[18] D. C. Appleby, How to improve your teaching with the course syllabus, APS Observer 7, 3 (1994).

[19] M. S. Palmer, L. B. Wheeler, and I. Aneece, Does the document matter? The evolving role of syllabi in higher education, Mag. Higher Learn. 48, 36 (2016).

[20] R. J. Harnish and K. R. Bridges, Effect of syllabus tone: Students' perception of instructor and course, Soc. Psychol. Educ. 14, 3 (2011).

[21] R. M. Perrine, J. Lisle, and D. L. Tucker, Effect of a syllabus offer of help, student age, and class size on 
college students' willingness to seek support from faculty, J. Exp. Educ. 64, 41 (1995).

[22] LivingPhysicsPortal.org.

[23] J. W. Creswell and V.L. Plano Clark, Designing and Conducting Mixed Methods Research, 2nd ed. (SAGE Publications, Inc., Thousand Oaks, CA, 2011).

[24] L. Rourke and T. Anderson, Validity in quantitative content analysis, ETR\&D 52, 1 (2004).

[25] G. A. Bowen, Document analysis as a qualitative research method, Qual. Res. J. 9, 27 (2009).

[26] Z. O'Leary, The Essential Guide to Doing Your Research Project (SAGE Publications, Inc., Thousand Oaks, CA, 2014).

[27] M. Vaismoradi, H. Turunen, and T. Bondas, Content analysis and thematic analysis: Implications for conducting a qualitative descriptive study, Nursing Health Sci. 15, 398 (2013).

[28] E. F. Redish, C. Bauer, K. L. Carleton, T. J. Cooke, M. Cooper, C. H. Crouch, B.W. Dreyfus, B. Geller, J. Giannini, J. Gouvea, M. W. Klymkowsky, W. Losert, K. Moore, J. Presson, V. Sawtelle, K. V. Thompson, C. Turpen, and R. K.P. Zia, NEXUS/Physics: An interdisciplinary repurposing of physics for biologists, Am. J. Phys. 82, 368 (2014).

[29] Committee on Professional Training, Undergraduate Professional Education in Chemistry: Guidelines and Evaluation Procedures (American Chemical Society, Washington, DC, 2003).

[30] L. W. Anderson et al. A Taxonomy for Learning, Teaching and Assessing: A Revision of Bloom's Taxonomy of Educational Objectives (Longman, New York, NY, 2001).

[31] J. Watkins, J. E. Coffey, E. F. Redish, and T. J. Cooke, Disciplinary authenticity: Enriching the reform of introductory physics courses for life science students, Phys. Rev. ST Phys. Educ. Res. 8, 010112 (2012).

[32] J. Watkins and A. Elby, Context dependence of students' views about the role of equations in understanding biology, CBE Life Sci. Educ. 12, 274 (2013).

[33] R. M. Harden, Learning outcomes and instructional objectives: Is there a difference?, Med. Teach. 24, 151 (2002). 